\title{
Oceanography
}

CITATION

Lozier, M.S. 2016. TOS to pilot a mentoring program for ocean science graduate students. Oceanography 29(3):7-8, http://dx.doi.org/10.5670/oceanog.2016.65.

DOI

http://dx.doi.org/10.5670/oceanog.2016.65

COPYRIGHT

This article has been published in Oceanography, Volume 29, Number 3, a quarterly journal of The Oceanography Society. Copyright 2016 by The Oceanography Society. All rights reserved.

USAGE

Permission is granted to copy this article for use in teaching and research. Republication, systematic reproduction, or collective redistribution of any portion of this article by photocopy machine, reposting, or other means is permitted only with the approval of The Oceanography Society. Send all correspondence to: info@tos.org or The Oceanography Society, PO Box 1931, Rockville, MD 20849-1931, USA. 


\section{TOS To Pilot a Mentoring Program for Ocean Science Graduate Students}

After taking a break for the beach and a fair share of summer reads, it is time to get ready for another semester. My immediate focus is on preparation for my fall undergraduate course, but graduate education is never far from my mind these days. It has been a focus of TOS Council meetings for the past year, and I have been involved for some time in efforts to reimagine graduate education in the sciences here at Duke. In previous columns, I discussed the motivation for this reimagining, namely, the current job market for $\mathrm{PhDs}$ in science. Nationwide, only about $10 \%$ of PhD students in science, technology, engineering, and mathematics (STEM) fields go on to academic careers, a sobering statistic given that most graduate student training emphasizes such careers. In this column, I turn to thoughts on how changes in graduate education might be approached.

A main challenge to reconfiguration of graduate education is its financial model. Financial support for graduate students is inextricably linked to faculty research programs and, in most major research universities, to undergraduate education, the latter via teaching assistantships. Thus, a comprehensive revision of graduate education cannot be seriously approached without understanding the constraints placed by these ties. If every student who entered graduate school paid his or her own way (undesirable and unlikely) or received a fellowship (desirable, yet unlikely), a vision for graduate education would focus solely on providing graduate students with the knowledge and skills required for the pursuit of career options that included, but were not limited to, academia. Instead, the current funding model for graduate education constrains the degree to which students can pursue independent projects; work in collaborative teams; and acquire communication, entrepreneurial, and leadership skills-all desirable experiences for graduates looking for work in a wide array of professional careers.

And so, as I have written before, the ocean science community, in conjunction with the federal agencies that support ocean research, should consider a "sea change" in how graduate education is funded. Possible changes include shifting resources from research assistantships toward fellowships; funding master's education; and "rightsizing" the balance among graduate student, postdoctoral, and early career support. These are not easy changes, but then, it is not easy to see graduate students with dampened expectations of academic careers.
Funding changes alone will not make the fix. Universities must also evaluate graduate education in the sciences in light of these statistics. Even without structural changes in graduate student funding, universities can expand career opportunities for their graduates by (1) developing joint-degree programs, (2) providing courses and/or workshops that focus on the knowledge and skills needed for nonacademic employment, (3) permitting collaborative research projects, and (4) requiring rigorous training in oral and written communication, with an emphasis on public scholarship. Admittedly, these changes require a cultural shift in graduate education, yet the shift in job statistics lays bare our responsibility to make these changes.

All of this brings me back to TOS. It's easy to call out the funding agencies and universities as the change makers. But, aside from prodding universities and funding agencies to act, what role can our society play in effecting change? Following the TOS Town Hall on graduate education at the 2016 Ocean Sciences meeting in New Orleans, the TOS Council discussed just this question. And our answer is two-pronged. First, the Council would like to expand TOS's membership to include a larger number of nonacademic oceanographers. Instead of mainly being an academic oceanographic society, we would like to be an academic and professional oceanographic society that includes much broader membership from industry, nonprofits, and government agencies. This expansion would make possible the second prong of our response to the changing job market, formation of a mentoring program where current graduate students are mentored by senior oceanographers with a variety of careers, inside and outside of academia. In essence, we think The Oceanography Society can and should create networks that would expand and facilitate graduate student career pathways. We cannot do much about funding models or curricular changes, but, as a society, we can connect people.

And we have model for this effort. Since 2008, MPOWIR (Mentoring Women in Physical Oceanography to Improve Retention), a community-initiated and community-led mentoring program funded by the US National Science Foundation, Office of Naval Research, National Aeronautics and Space Administration, and Department of Energy has focused on improving the retention of women in physical oceanography through mentoring. The MPOWIR program has several 
elements, but one of the most successful has been MPOWIR mentoring groups, which are composed of five to seven students, postdocs, or early career scientists and two senior oceanographers as lead members. The groups meet monthly for about an hour via teleconference for the purpose of providing confidential mentoring, including peer mentoring, for the junior group members. Each group has an expected lifetime of approximately two years. Survey results from group participants reveal high satisfaction with this mentoring element, and early indications are that MPOWIR is moving the needle on retention.

The TOS Council plans to explore whether the MPOWIR model can serve our goal of exposing current graduate students, men and women alike, to different career paths. The idea is to form mentoring groups of students across the country and pair them with two senior oceanographers, each with a different career. While we think that students in these groups will learn more about oceanography careers, we expect the biggest advantage to be that a student will learn how his or her own skills and interests are suited to a particular career. As with MPOWIR, it is easy to see how a senior oceanographer obtained his or her job, but it is more difficult to see how to get there yourself. This is where mentoring comes in.

So, we want to give it a try. We will advertise the start of two pilot mentoring groups this fall and launch the groups in January of 2017. It's a small start, but nonetheless a step in the right direction. Basically, it is an opportunity for this society of professional oceanographers (of all stripes) to take responsibility for the next generation of oceanographers. Or, more colloquially, it gives us a chance to show them the ropes.

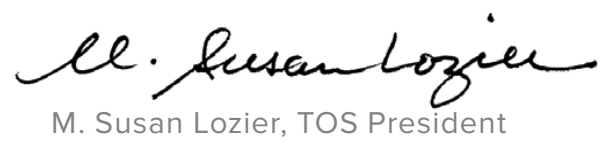

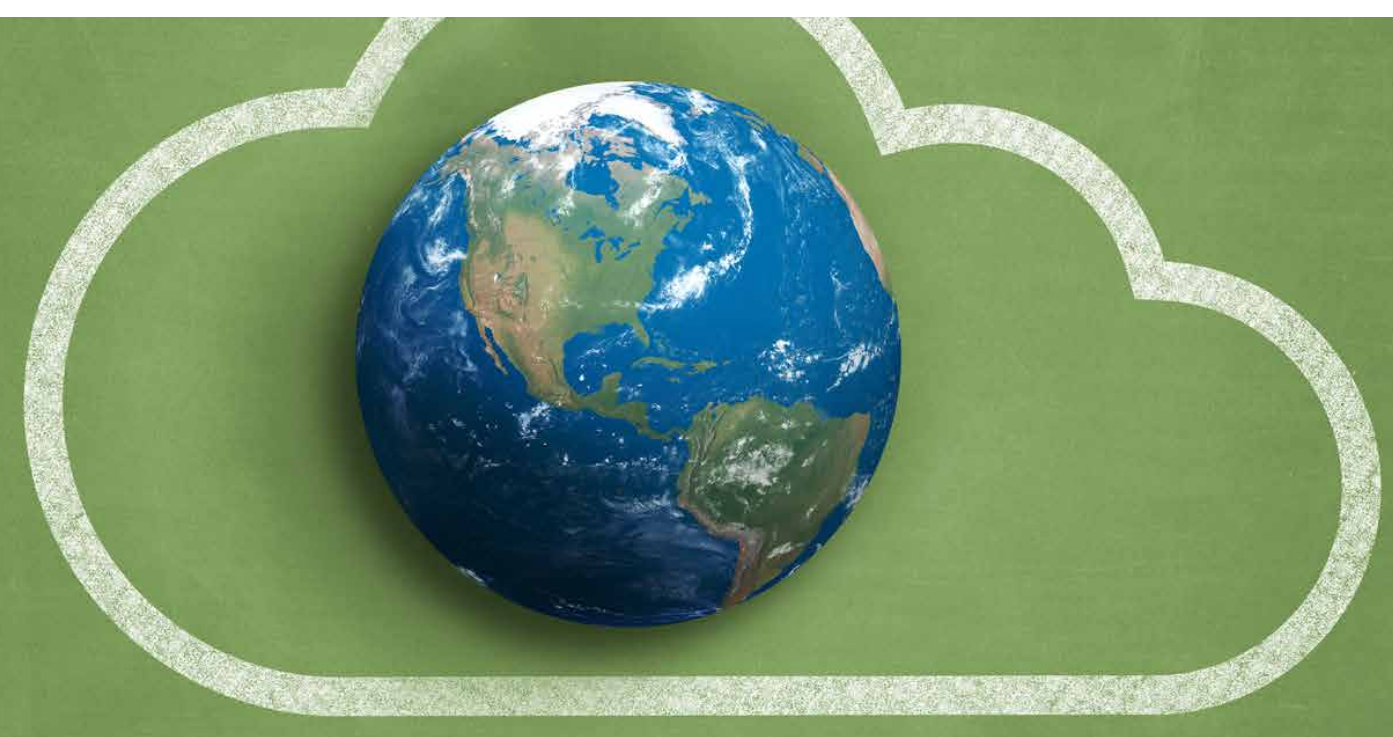

Call for Contributions to the New Web Portal RESOURCES FOR GRADUATE STUDENTS

\author{
http://tos.org/opportunities
}

The Oceanography Society has created a new Web page to serve as a resource for ocean sciences graduate students. This portal contains information on fellowships, scholarships, summer positions, volunteer opportunities, links to useful articles, and ship time/fieldwork opportunities.

\title{
Do you have suggestions or contributions for this page?
}

Please contact us at magazine@tos.org. 